\title{
The Inlet Engine Valves Grinding Using Different Types of Cutting Fluids and Grinding Wheels
}

\author{
Eraldo Jannone da Silva ${ }^{a}$, Eduardo Carlos Bianchi ${ }^{b}$ *, \\ João Fernando Gomes de Oliveira ${ }^{c}$, Paulo Roberto de Aguiar ${ }^{d}$ \\ ${ }^{a}$ University of São Paulo - USP, São Carlos Engineering School - EESC \\ 13560-250 São Carlos - SP, Brazil \\ ${ }^{b}$ São Paulo State University - UNESP, Mechanical Engineering Department \\ C. P. 473, 17033-360 Bauru - SP, Brazil \\ ${ }^{c}$ University of São Paulo - USP, São Carlos Engineering School - EESC \\ 13560-250 São Carlos - SP, Brazil \\ ${ }^{d}$ São Paulo State University - UNESP, Electrical Engineering Department \\ C. P. 473, 17033-360 Bauru - SP, Brazil
}

Received: November 05, 2001; Revised: March 21, 2002

\begin{abstract}
In this paper an experimental research is presented in which different types of cutting fluids (a cutting oil and three different types of soluble oils) and grinding wheels (alumina and vitrified $\mathrm{CBN}$ ) were tested in the inlet engine valves grinding. As evaluation parameters the workpiece residual stress and the grinding wheel wear were analyzed. The cutting fluid and the grinding wheel types adopted resulted in changes in all the parameters, due to the different lubricant abilities among the fluids and due to the differences in the mechanical and thermal properties among the abrasives tested. For grinding this steel, the CBN wheel is the best choice, mainly due to compressive residual stress results obtained for all cutting fluids tested. The cutting oil is the most adequate cutting fluid to be used, due to its higher lubricity and ability in keeping the wheel sharp for longer periods of time, reducing the overall grinding energy and the thermal damage.
\end{abstract}

Keywords: grinding wheel, cutting fluid, residual stress

\section{Introduction}

The grinding process is widely used to produce surfaces of good dimensional accuracy and finish (Moulik et al., 2001). Besides these features, the grinding process must ensure that the designed mechanical properties of the workpiece will not be negatively affected.

During grinding, due to the chip formation mechanism, a great part of the produced energy is converted into heat and high temperatures are generated at the interface between the abrasive grain and the workpiece. These temperatures are the main source of damage on the machined surface (Shaw, 1984). It was found that thermal stresses generated in the grinding process were the primary cause of the tensile residual stresses (Chen et al., 2000), which cause a reduction in the service life under stress corrosion or fatigue conditions. In many cases, the thermal damage of the workpiece limits the productivity of advanced grinding methods.

Fluid application in grinding process is becoming more important as higher stock-removal rates, higher quality, and longer wheel life are sought. Selection of an efficient way to apply it, and straight follow the standard procedures of cutting fluid maintenance are extremely important to meet productivity goals and can be as important as the selection of the grinding wheel specification (Webster, 1995). According to Webster (1999), the fluid application that does not take the advantage of the wheel ability to act as a pump (Guo \& Malkin, 1992) will cause high contact arc temperatures up to the point when the fluid quenches the bulk material just after the wheel has passed by. This post grinding quenching can create undesirable tensile stress in the workpiece surface and can also overheat the wheel bond and abrasive materials. Consequently, the optimization of 
the grinding process implies not only the selection of the right grinding wheel and cutting parameters but also the adoption of the most effective grinding fluid and its correct way of application.

This paper presents a comparative study in which the performance of different types of cutting fluids and grinding wheels was evaluated in the inlet engine valves grinding through the following parameters: the workpiece residual stress and the radial wheel wear. As these valves are submitted to fatigue conditions in service, special attention was given in the residual stress results analyze. This parameter was the main factor to be considering in this comparative study. Thus, the most important concepts of residual stress in grinding are presented. Finally, the best combination of grinding wheel and cutting fluid to perform this grinding operation is determined.

\section{Residual Stresses In Grinding}

In general, residual stresses in grinding are primarily generated due to three effects (Chen et al., 2000):

- Thermal expansion and contraction during grinding;

- Phase transformations due to high grinding temperatures;

- Plastic deformation caused by the abrasive grains of the grinding wheel.

The first two effects described above generate the thermally-induced residual stresses in grinding and the last one the mechanically-induced ones. Combinations of the thermal and mechanical effects are possible and the resultant stress is determined by whichever effect is stronger. Compressive residual stresses can increase the fatigue life and the mechanical properties of the ground component (Malkin, 1989). If tensile residual stresses remain in the surface, the subsequent service life is reduced under stress corrosion or fatigue conditions.

The control of the maximum grinding temperature is the key for achieving favorable grinding residual stresses. It can be done by the reduction of the generated heat in grinding and by favoring its easier dissipation from the grinding zone, reducing the amount of heat that flows through the workpiece. This can be achieved by the correct selection of the cutting conditions and the use of the most appropriated cutting fluid and grinding wheel types.

\subsection{The influence of cutting fluid type in the residual stresses}

Different types of cutting fluids can lead to different residual stress results. In Table 1 are presented the seven major characteristics of the four main types of grinding fluids (Webster, 1995).

Among the characteristics presented in Table 1, the lubricity of grinding fluid is the main contributor for low stress
Table 1. Grinding fluids characteristics (1-worst; 4-best), (Webster, 1995).

\begin{tabular}{lcccc}
\hline & Synthetic & $\begin{array}{c}\text { Semi } \\
\text { synthetic }\end{array}$ & $\begin{array}{c}\text { Soluble } \\
\text { oil }\end{array}$ & $\begin{array}{c}\text { Cutting } \\
\text { oil }\end{array}$ \\
\hline $\begin{array}{l}\text { Heat removal } \\
\text { by convection }\end{array}$ & 4 & 3 & 2 & 1 \\
Lubricity & 1 & 2 & 3 & 4 \\
Maintenance & 3 & 2 & 1 & 4 \\
Filterability & 4 & 3 & 2 & 1 \\
Environmental & 4 & 3 & 2 & 1 \\
Cost & 4 & 3 & 2 & 1 \\
Wheel life & 1 & 2 & 3 & 4 \\
\hline
\end{tabular}

in grinding. In order to reduce the thermal damage and to prevail compressive residual stresses, the cutting fluids need to guarantee chip formation instead of plowing, keeping the abrasive grain sharp, reducing the friction coefficient between grain and workpiece. Thus, less heat will be generated during the grinding process (Hitchiner, 1990), decreasing the specific grinding energy (Malkin, 1989). This can be done by selecting a grinding fluid with the appropriate lubricity. The use of cutting oils results in a reduction in the specific grinding energy, decreasing the workpiece temperature. Besides, there is a reduction in the rate of growth of wear flat on the grits (Webster, 1995) increasing the wheel life (See Table 1). Furthermore, when grinding hardened steels, the lower cooling rate of the cutting oils can prevent the formation of untempered martensite, which is resulted from the overheating of the surface followed by rapid quenching, leading to tensile residual stresses in the subsurface.

The higher heat transfer ability of the soluble oils could be an advantage in decreasing the generated heat in the grinding zone. Although, due to the film boiling effect, the convective cooling in the grinding zone and the reduction of the workpiece temperature can usually be neglected (Lavine $\&$ Malkin, 1990). The film boiling phenomenon affects water-soluble fluids and cutting oils in a different way (Yasui \& Tsukuda, 1983). As reported by the authors, the occurrence of the film boiling in water-soluble fluids lowers the heat transfer coefficient of the fluid to almost the same as air. As a result, the cooling performance in these fluids deteriorates to become almost the same as in dry. Since the physical properties of water-soluble fluids are almost the same as water, the film boiling seems to occur at the temperature in slight excess of $100{ }^{\circ} \mathrm{C}$. On the contrary, the cutting oil is a mixture of different oils having different boiling temperature and its average boiling point is about $300{ }^{\circ} \mathrm{C}$. Therefore, at a rougher grinding conditions, the effect of film boiling is more critical when a water-soluble fluid is applied. 
After choosing the most appropriated cutting fluid type with the appropriated lubricity, it must be ensured that the fluid will be applied in the most effective way. The main problem with coolant application is the air barrier that has to be overcome. It can be done by matching the coolant jet speed to the wheel peripheral velocity. However, poor nozzle design and machine plumbing lead to a dispersed jet when the fluid pressure is increased in order to raise the jet exit velocity (Webster, 1999).

The purposed solutions include the installation of special nozzles designed to increase the jet coherence. An example is the round nozzle purposed by Webster (1995), which is based on the fire hose nozzles (Rouse et al., 1952). A drawback in attempting to increase the cutting fluid jet velocity is the required pressure to accelerate the fluid. The velocity of the coolant is proportional to the square root of the nozzle entrance pressure. In other words, four times more pressure is required to double the jet velocity. In the high speed grinding (above $100 \mathrm{~m} / \mathrm{s}$ ) the pump pressure requirements can easily surpass 40 bar (Webster, 1999) leading to pump cost limitations. A solution for cutting fluid application in high speed grinding is the use of shoe nozzle (Klocke et al., 2000). This nozzle geometry permits the cutting oil feeding under almost no pressure to a reservoir inside the nozzle. From here, it is accelerated by the grinding wheel itself into a narrow gap, merging near the contact point, where it travels at the circumferential wheel velocity, clinging to the surface of the grinding wheel.

An effective filtration is also an important factor affecting the cutting fluid performance, specially when CBN wheels are used. According to Leal (1993), the grinding wheel will become loading earlier if the cutting fluid has an excessive amount of abrasive particles and chips. As a result, the number of dressing operations will increase, resulting in an increase of the grinding costs.

\subsection{The influence of grinding wheel type in the residual stresses}

The grinding wheel specification and its topography have significant influence in the generated heat and its dissipation through the grinding zone.

Due to the better mechanical and thermal proprieties of the CBN grains when compared to the alumina ones (See Table 2), 60-75 percent of the grinding energy is transported to the workpiece as heat with an aluminum oxide abrasive wheel, as compared to only $20 \%$ with CBN one (Kohli et al., 1995), leading to different energy partition (Chen et al., 2000). Consequently, more heat is conducted out of the grinding zone through the grinding wheel instead of the workpiece (Lavine et al., 1989).

The thermal damages are decreased when CBN wheels are used (Malkin, 1985). The burn rarely occurs and the
Table 2. Mechanical and thermal proprieties of the CBN and alumina grains.

\begin{tabular}{lcc}
\hline Grain Type & $\begin{array}{c}\text { Thermal conductivity } \\
\left(\mathrm{cal} /{ }^{\circ} \mathrm{C} . \mathrm{cm} . \mathrm{s}\right)\end{array}$ & $\begin{array}{c}\text { Knoop hardness } \\
\left(\mathrm{kgf} / \mathrm{mm}^{2}\right)\end{array}$ \\
\hline CBN & 3.3 & 4,500 \\
Alumina & 0.08 & 2,500 \\
\hline
\end{tabular}

residual stresses are mainly, compressive (Brinksmeier et al., 1982, Tönshoff \& Grabner, 1984; Vansevenat, 1989). Although, $\mathrm{Al}_{2} \mathrm{O}_{3}$ grinding wheels can also generate compressive residual stress but only after dressing or when a suitable cutting fluid with the appropriate lubricity is applied. With the increase of the amount of removed material, the residual stresses increase towards tension. On the other hand, in terms of residual stress, the CBN wheels are less sensitive to the cutting fluid type applied and are much less sensitive against material removal variations guarantying compressive residual stresses after long grinding times (Brinksmeier et al., 1982). It is based on the fact that the wear mechanisms of the CBN and alumina grains are quite different. When grain blunting is frequently observed in alumina grains, which means an increase in the generated friction heat, no blunting can be observed by scanning electron microscope in CBN grain. In this case, only splintering is observed, which does not restrict the sharpness. Therefore, less heat arises in the cutting zone with the consequence that only compressive residual stresses are produced. With increasing CBN wheel concentration, the residual stresses shift to compression (Brinksmeier et al., 1982).

The bond material is also a parameter affecting the residual stress. In general, $\mathrm{Al}_{2} \mathrm{O}_{3}$ wheels have ceramic bond whereas different types of bonds are offered for CBN wheels, depending on the operation tasks. The higher the thermal conductivity of the bond system, the lower the workpiece energy partition. The wheel structure, hardness and concentration also influence in the residual stress. A soft wheel can require more dressing time, however it can be advantageous because less stress is produced caused by constantly grain renew. An open grinding wheel structure can prevent premature wheel loading, decreasing the generated friction heat. When using wheels with small grains, the tangential forces are lower, which does lead to a reduced amount of generated heat. With increased CBN wheel concentration, the residual stress shift to compression (Brinksmeier et al., 1982).

The wheel dressing is found to be a parameter with a great impact upon the grinding wheel topography and thus upon the heat generation in the cutting process (Brinksmeier et al., 1982). Coarse dressing produces a wheel surface that is open and free cutting. On the other hand, a closed grain 
structure in the wheel results in wheel surfaces that are not free cutting which leads to an increased thermal impact. Tensile residual stresses increase although the surface quality is improved in most cases.

\section{Test Methodology}

The grinding tests of the inlet engine valves were performed in a CNC cylindrical grinding, SULMECÂNICA, model RUAPH 515-CNC. The material of test specimens was the chrome-silicon steel SAE HVN-3 (DIN X $45 \mathrm{CrSi}$ 93), tempered and quenched, $60 \mathrm{HRc}$, in a cylindrical shape. Its final diameter was $23.8 \mathrm{~mm}$ and it was $35 \mathrm{~mm}$ long. Before the grinding tests, and after the tempering, the test specimens were turned, in order to correct their dimensional and geometrical errors. This operation was performed using an EMCO turn, model Turn 120, with the following cutting conditions: cutting speed $\left(v_{c}\right)=67 \mathrm{~m} / \mathrm{min}$; feed $(f)=50 \mathrm{~mm} / \mathrm{min}$. The insert used has the CCMT $09 \mathrm{~T} 308$ - UR ISO specification and a SCLCL 1212 D09 tool holder. The cutting fluid used was $5 \%$ soluble oil.

Four different types of cutting fluid were tested: a cutting oil, an E.P. mineral oil without chlorine additives and nitride; $8 \%$ soluble oil (vegetable emulsion), a biodegradable vegetable soluble one; $8 \%$ soluble oil (mineral emulsion), a mineral emulsion with non-chlorine E.P. additives and $8 \%$ synthetic fluid. The cutting conditions applied in the grinding tests were: cutting speed $\left(v_{s}\right)=60 \mathrm{~m} / \mathrm{s}$; workpiece diameter $\left(d_{w}\right)=23.8 \mathrm{~mm}$; plunge speed $\left(v_{f}\right)=1.2 \mathrm{~mm} / \mathrm{min} ; h_{e q}=0.025 \mathrm{~mm}$; grinding wheel penetration $(a)=200 \mathrm{~mm}$, grinding width $(b)=15 \mathrm{~mm}$. The sparkout time was 5 seconds.

In the tests, the cutting fluid application system was improved. A new round nozzle based on Rouse et al. (1952) was developed, with exit diameter $\left(D_{n}\right)$ equal to $6 \mathrm{~mm}$. It is shown in Fig. 1. A 5-bar pressure pump was installed. It permitted the maximum jet velocity $\left(v_{j}\right)$ equal to $34 \mathrm{~m} / \mathrm{s}$ (approx. flow rate equal to $3,500 \mathrm{l} / \mathrm{h}$ ) for the less viscous cutting fluid and $31 \mathrm{~m} / \mathrm{s}$ (approx. flow rate equal to 3,100 1/h), when using the most viscous cutting fluid (cutting oil). Thus, the maximum ratio $v_{j} / v_{s}$, assigned as $V^{*}$, applied in this research was, approximately, equal to 0.5 . The round nozzle scheme and the one installed in the grinding machine under operation are also shown in Fig. 1.

The tests were performed using a 19A100SVHB grinding wheel, dressed with dressing overlap $(U d)$ equal to 8 , reproducing in the laboratory the same dressing condition and grinding wheel adopted in the TRW factory, where this grinding is performed on semi finishing and finishing operations. In order to verify the grinding wheel type influence in the outlet parameters, a CBN grinding wheel B76R125V12 was also tested, trued using a diamond rotator disc with speed-ratio equal to 0.7 positive, i.e., the ve-

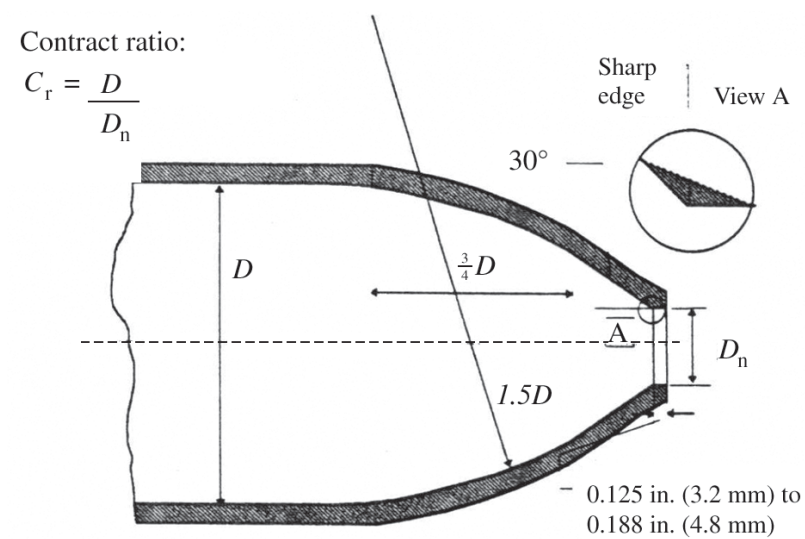

$C_{r}$ is the contraction ratio.

$D$ is the diameter of nozzle feed pipe.

$D_{n}$ is the diameter of nozzle exit.

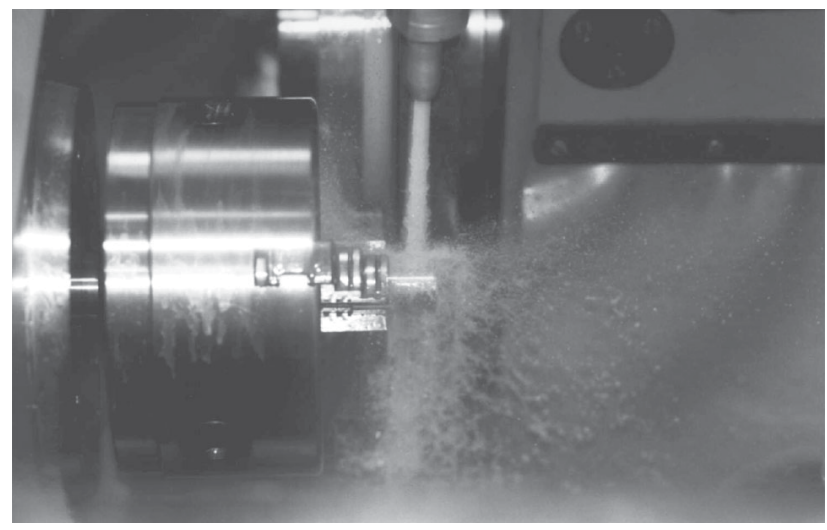

Figure 1. On the top, the round nozzle scheme developed based on Rouse et al. (1952) and Webster (1995). On the bottom, the new 6-mm- $D_{n}$ round nozzle under operation.

locity of the rotator disc was 0.7 of the grinding wheel velocity.

In order to verify the influence of the grinding wheel wear in the outlet parameters, for each trial, varying the cutting fluid and grinding wheel types, 103 grinding cycles were performed with the cutting conditions mentioned later. The radial wheel wear was also evaluated in order to verify the cutting fluid influence in this parameter.

The residual stress were measured using a 4 circles difractometer SIEMENS, model D5000. To the determination of the nominal values of residual stress were used the $\sin ^{2} \psi$ two exposure method, according to the Information Report SAE J784a (1971). In this experimental procedure, it is possible to analyze the normal residual stress $(\sigma)$ and the shearing stress $(\tau)$ adjusting curves that related the crystallography plane interplanar distances $(d)$ versus $\sin ^{2} \psi$, where $\psi$ is the workpiece tilt angle. The X-ray residual stress measurements were performed at the Materials Characteri- 
zation Center (CCDM), located at the São Carlos Federal University (UFSCar), in São Carlos, Brazil. The Fig. 2 presents the direction of the measured residual stress.

The residual stress values obtained refer to the stresses measured at $15 \mathrm{~mm}$ below the surface, due to the $\mathrm{x}$-radiation type used (Chrome) and the atomic plane (110) of the electrolytic iron (alpha phase) analyzed. The Young's modulus and the Poison coefficient applied values were in agreement with appropriated technical data for the electrolytic iron, plane (110). The $2 \theta$ scanning angle range was 65 to 72 degrees, with steps of 0.1 degree, with exposure time equal to 4 seconds. The workpiece tilt angle $(\psi)$ range was -60 to 60 degrees, with measures performed at each 10 degrees.

The wheel wear profile was measured a TESA displacement gauge, model TT10.

\section{Results and Discussion}

\subsection{Residual stress results}

In order to verify the reliability of the residual stress measurements, preliminary tests were performed, which are shown in Fig. 3.

Two different test procedures were applied. In the first test, different measurements were performed at two different angular positions in the same workpiece distant 90 degrees. The results shown in the Fig. 3 indicates that there is a lower variability in relation to the observed mean value, with a variation coefficient $(V C)$ (standard deviation divided by the mean) equal to $9.54 \%$. A second test was performed in which consecutive measurements were performed in the same workpiece position without removing the workpiece from the difractometer. In this case, the $V C$ was equal to $1.07 \%$. In both tests, the residual stress type (tension or compression) in the consecutive measurements was maintained.

Measured residual stress direction

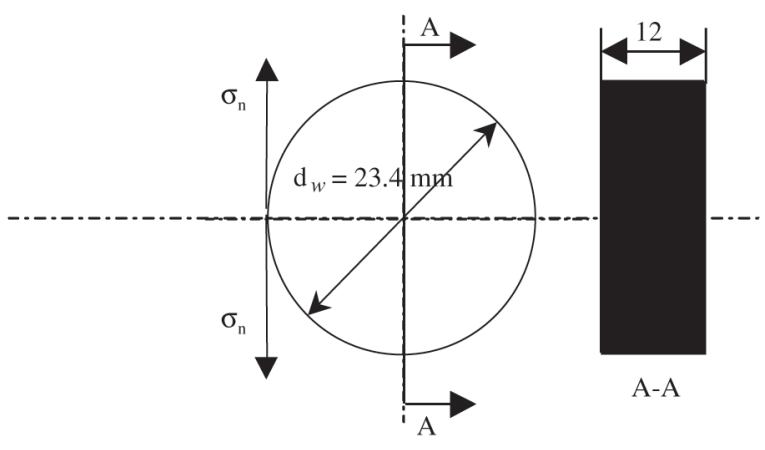

Dimensions in $\mathrm{mm}$

Figure 2. Measured normal residual stress direction.
Based on these results, it was determined that one residual stress measurement in a single angular position would be performed for each grinding test sample.

The average residual stress values after tempering and turning were $425 \mathrm{MPa}$ tensile and $450 \mathrm{MPa}$ compression, respectively. Analyzing these results, it was possible to verify that, after turning, all the test specimens presented compression residual stresses, due to the machining process used to correct their geometrical and dimensional errors. The state of compression indicates that, before the grinding tests, nonthermal damage was imposed during the turning.

The Figs. 4 and 5 present the residual stress values for each cutting fluid and grinding wheel tested, when using conventional and CBN grinding wheels, respectively.

Analyzing the Figs. 4 and 5, it is possible to verify that, after the dressing operation, for the first grinding cycle, almost all of the cutting fluids can generate compressive residual stress, except the synthetic one, when grinding using the conventional grinding wheel (See Fig. 4). It seems that, even using the conventional wheel compressive residual stresses can be generated for the first grinding cycles. With the grinding wheel still sharp, less heat is generated and, even with the poor conductivity properties of the conventional grinding wheel grains it is still possible to expect compressive residual stress. This fact was also observed by Brinksmeier (1986). Although, due to the lower abrasive grain hardness and thermal conductivity when compared with the CBN grains, as the amount of removed material increases, the residual stresses measured after grinding using the conventional grinding wheel shift to tension, for all the water-soluble cutting fluids tested. In all the CBN grind-

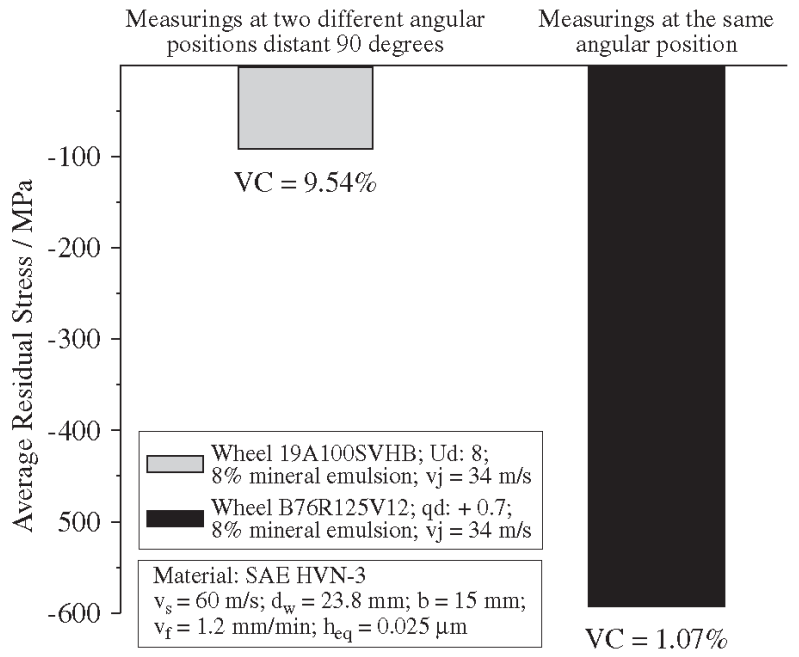

Figure 3. Residual stress measurements - preliminary tests (where $V C$ is the variation coefficient). 


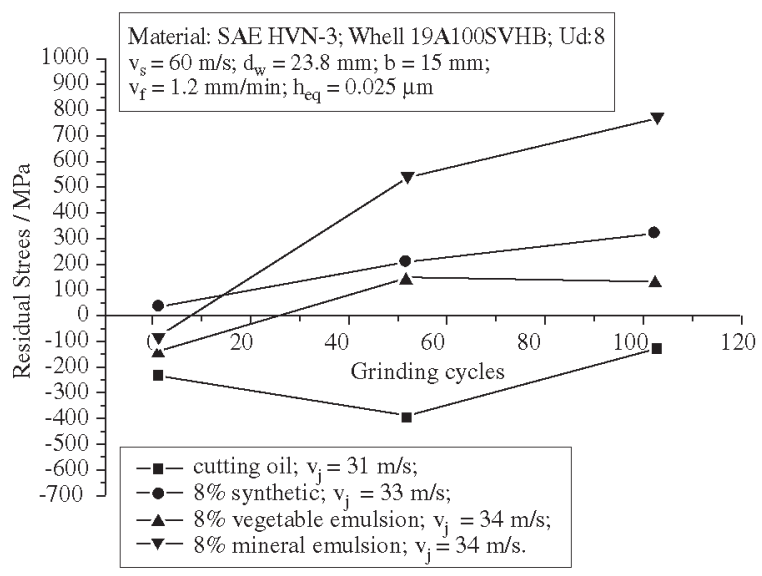

Figure 4. Residual stress values measured after the grinding tests when using the conventional grinding wheel.

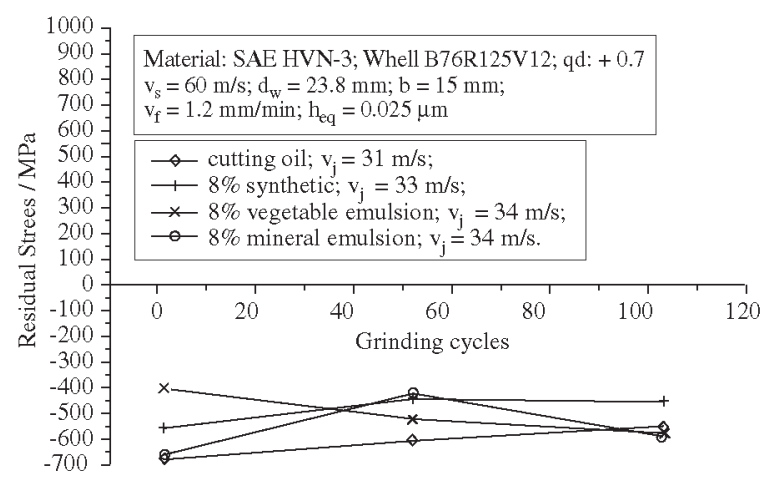

Figure 5. Residual stress values measured after the grinding tests when using the $\mathrm{CBN}$ grinding wheel.

ing tests, the generated residual stresses are compressive and presented a stable behavior, guaranteeing compressive values for all the grinding cycles. The lower energy partition obtained when using $\mathrm{CBN}$ wheel combined with the great ability of keeping the wheel sharp lead to a double benefit. Less heat is generated and it is more easily dissipated through the wheel instead of the workpiece. There is a decrease in the maximum grinding temperatures and the thermal damage rarely occurs. The mechanical action of the abrasive grains is predominant over the thermal effects, leading to compressive residual stresses.

As also observed by Brinksmeier et al. (1982), the fine dressing operation performed in the conventional grinding wheel $(U d=8)$ created a closed grain structure in the wheel. Combined with the poor mechanical and thermal abrasive grain properties, these facts resulted in wheel surfaces that are not free cutting, which accelerated and increased the thermal impact.

Regarding only to the grinding wheel type, the CBN one presented the best residual stress results, do not depending on the cutting fluid type.

It was possible to verify that the cutting fluid type has a great influence in the residual stress behavior, mainly when conventional grinding wheel is used.

According to the results, even so the cutting oil has a poor convection heat transfer when compared with the water-based ones, it was the only one that could result on the workpiece compressive residual stresses, for all the cycles, when using the conventional grinding wheel. This fact is related with the superior lubricant ability of this cutting fluid. As also observed by Hitchiner (1990), the cutting oil promotes the cutting rather than plowing and sliding, keeping the wheel sharp, due to the friction reduction between the abrasive grain and the workpiece. Consequently, there is a decrease in the specific grinding energy (Malkin, 1989), in the maximum grinding temperatures and in the thermal damages. This feature of residual stress reduction when using cutting oil and conventional grinding wheel were also observed by Brinksmeier et al. (1982). Even the water-miscible cutting fluids having a higher heat transfer capability when comparing with the cutting oil, this advantage cannot imply in any improvement in the residual stress, due to the film boiling effect. It seems that the cutting oil with higher lubricant capability can outweigh its poor heat transfer ability through the reduction of friction and the abrasive wear, leading to less heat generation.

The same behavior of decreasing the residual stresses when using different types of cutting fluids could not be observed in the $\mathrm{CBN}$ grinding wheel tests. It seems that due to the superior thermal and mechanical properties of its abrasive grains, the amount of removed material performed in each test (103 grinding cycles removing, in volume, $194 \mathrm{~mm}^{3}$ of material) were not sufficient enough to cause sharpness reduction in the $\mathrm{CBN}$ grinding wheel.

Consequently, in order to evaluate the ability of the cutting fluid type in reducing the grinding wheel wear, the radial wheel wear was measured.

\subsection{Radial wheel wear results}

The radial wheel wear values, measured after each test, varying the cutting fluid and the grinding wheel types were presented in Fig. 6.

Analyzing the radial wheel wear results, it can be noticed that the lower values were obtained in the CBN tests. It was already expected due to its grain better mechanical properties (Knoop hardness) when comparing with the $\mathrm{Al}_{2} \mathrm{O}_{3}$ one.

It was also possible to verify that the wheel wear can be significantly reduced if cutting fluids with high lubricant ability were used. The cutting oil significantly reduced the radial wheel wear for both grinding wheel tested. As ob- 


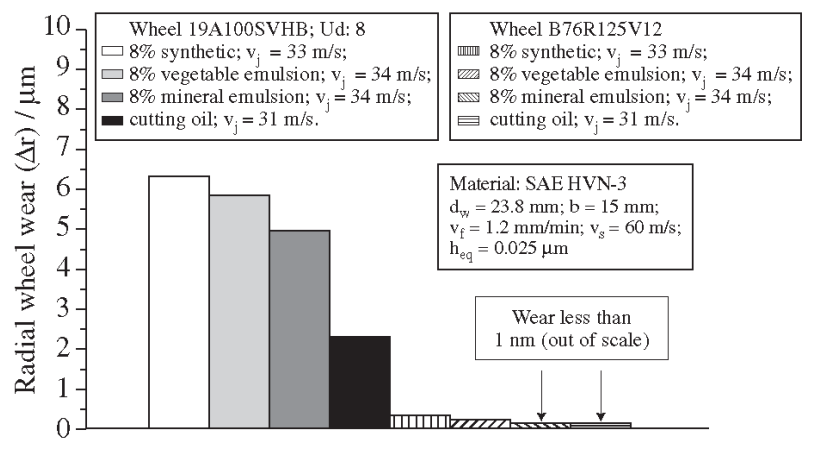

Figure 6. Radial wheel wear values.

served by Carius cited by Webster (1995) and Hitchiner (1990), the cutting oil, due to its higher lubricity, makes the wheel sharper, inhibiting glazing and capping of the grits by the decrease of the coefficient of friction. When using the conventional grinding wheel, it can be seen that the decrease in the lubricity capacity of the cutting fluid (cutting oil to the synthetic) leads to the increase in the radial wheel wear. The thermal grain shock caused mainly when the combination of $\mathrm{Al}_{2} \mathrm{O}_{3}$ grit and water-based coolants is used may have a contribution in the higher wheel wear detected in the tests. The significant reduction in the abrasive wheel wear when using the cutting oil confirms its ability in reducing the generated energy and keeping the wheel sharp, due to the friction reduction between the abrasive grain and the workpiece. This reduction in the generated heat permitted the prevailing of compressive residual stresses when grinding with the conventional wheel and oil as a cutting fluid.

According to the wear results, the cutting fluid type can drastically effect the behavior of the CBN wheels. Due to its poor induced porosity, the bond wear due to chip abrasion is critical and can be accelerated depending on the cutting fluid type. The wheel wear was completed eliminated when cutting fluids with high mineral oil content were used (see results for cutting oil and mineral emulsion). Under pressure, the lubricant ability of these fluids can decrease the friction between the workpiece and grain and, chips and bond. Besides, due to the film boiling, as observed by Leal (1993), when using water-soluble fluids, water vapor is formed and can reacted with the $\mathrm{CBN}$ forming the $\mathrm{B}_{2} \mathrm{O}_{3}$ in the $\mathrm{CBN}$ grain surface, preventing its oxidation. Although, as the $\mathrm{B}_{2} \mathrm{O}_{3}$ is soluble in water, the oxidation is still running, causing the degradation of the cutting edges of the CBN grains, accelerating its degradation. When using the cutting oil, with consequently no water present, this chemical reaction do not occur, preventing the chemical degradation of the CBN grains. The significance of this mechanism is still unknown, since its verification and measurement is difficult to perform.

\section{Conclusions}

According to the results obtained in this research, the authors conclude that:

- The use of CBN grinding wheels can significantly reduce the thermal damage in grinding, and, consequently, permit the generation of compressive residual stresses on the ground material surface even when a cutting fluid with poor lubricity is used.

- The lubricity of the cutting fluid is the key factor for its performance and can sensibly influence the grinding residual stresses (mainly in the alumina wheels) and the radial wheel wear.

- The cooling properties of the cutting fluids can be neglected and don't cause any improvement in the reduction of the grinding zone temperature and in prevailing compressive residual stresses.

- For the inlet engine valves grinding, regarding to the residual stresses and radial wheel wear results, the CBN wheel and the cutting oil are the best combination to perform this grinding operation.

\section{Acknowledgments}

This research was performed in FE - UNESP - Bauru São Paulo, in collaboration with the NUMA (OPF Group), located in the EESC - USP São Carlos - São Paulo, and was supported by FAPESP and by the following companies: Houghton do Brasil, Master Diamond Ferramentas ltda., TRW do Brasil, De Beers do Brasil and Saint Gobain Abrasives.

\section{References}

1. Brinksmeier, E. "A Model for the Development of Residual Stresses in Grinding", In: NIKU-LARI, A. Advances in Surface Treatments. 5.ed. Pergamon Press, v. 5, p.173-189, 1986.

2. Brinksmeier, E.; Cammett, J.T.; König, W.; Leskovar, P.; Peters, J.; Tönshoff, H.K. "Residual Stresses - Measurement and Causes in Machining Processes", Annals of the CIRP, v. 31/2, p. 491-510, 1982.

3. Chen, X.; Rowe, W.B.; McCormack, D.F. "Predicting the Transitional Boundary of Tensile Residual Stress in Grinding", Abrasives Magazine, Feb. /Mar. p. 28-35, 2000.

4. Guo, C.; Malkin, S. "Analysis of fluid through grinding zone". ASME Journal of Engineering for Industry, v. 114, p. 427-434, 1992.

5. Hitchiner, M.P. "Precision Grinding Systems for Production Grinding with Vitrified CNB" SME Technical Paper MR90-507, p. 1-11, 1990.

6. Klocke, F.; Baus, A.; Beck, T. "Coolant Induced Forces in High Speed Grinding with Shoe Nozzles", Annals of 
the CIRP, v. 49/1, p. 241-244, 2000.

7. Kohli S.P.; Guo, C.; Malkin, S. "Energy Partition for Grinding with Aluminum Oxide and CBN Abrasive Wheels". ASME Journal of Engineering for industry, v. 117, pp 160-168, 1995.

8. Lavine, A.S.; Malkin, S. "The Role of Cooling in CreepFeed Grinding", International Journal of Advanced Manufacturing Technology, v. 110, p. 1, 1990.

9. Lavine, A.S.; Malkin, S.; Jen, T.C. "Thermal Aspects of Grinding with CBN Abrasives", Annals of the CIRP, v. 38/1, p.557-560, 1989.

10. Leal, J. "La filtración en los processos de retificado com muelas de borazon", Filtrations News, v. VIII, p. 1-8, 1993.

11. Malkin, S. "Current Trends in CBN Grinding Technology", Annals of the CIRP., v. 34/1, p. 557-560, 1985.

12. Malkin, S. "Grinding Mechanisms" e "Grinding Temperatures and Thermal Damage", In: Malkin, S. Grinding Technology: theory and applications of machining with abrasives. 1.ed. Chichester, Ellis Horwood Limited, Cap. 5 e 6, p.108-171, 1989.

13. Moulik, P.N.; Yang, H.T.Y.; Chandrasekar, S. "Simulation of thermal stresses due to grinding", International Journal of Mechanical Sciences, v. 43, p. 831-851, 2001.
14. Rouse, H.; Asce, M.; Howe, J.W.; Metzler, D.E. "Experimental Investigation of Fire Monitors and Nozzles, $117^{\text {th }}$ ASCE Transactions, 1952.

15. SAE J784a, "Residual Stress Measurement by X-ray Diffraction" Society of Automotive Engineers, Inc., Second Edition, p. 1-119, 1971.

16. Shaw, M.C. "Grinding Temperatures", Proceedings of the $12^{\text {th }}$ North American Research Conference, Society of Manufacturing Engineers, Dearborn, MI, USA, p. 304, 1984.

17. Tönshoff, H.K.; Grabner, T. "Cylindrical and Profile Grinding with Boron Nitride Wheels" Proceedings of the $5^{\text {th }}$ International Conference on Production Engineering, Tokyo, p. 326-343, 1984.

18. Vansevenant, I.R.E. "An Improved Mathematical Model to Predict Residual Stresses in Surface Plunge Grinding", Annals of the CIRP., v. 36, p. 413-416, 1989.

19. Webster, J. "Selection of Coolant Type and Application Technique in Grinding". Supergrind, p. 205-218, 1995.

20. Webster, J. "Optimizing Coolant Application Systems for High Producing Grinding". Abrasives Magazine, Oct. /Nov. p. 34-41, 1999.

21. Yasui, H.; Tsukuda, S. "Influence of Fluid Type on Wet Grinding Temperature", Bull. Japan Soc. of Precision Engineering., v. 17, n. 2, p. 133-134, 1983. 